\title{
Tecendo Espaços e Experiências no Campo da Robótica Educacional para Fomentar o Interesse de Meninas pela área de Computação
}

\author{
Cristina Paludo Santos, Denilson Rodrigues da Silva, Alexandre dos Santos Roque, Juliana \\ Weinert da Silva, Marina de Souza Dal Ben
}

Universidade Regional Integrada do Alto Uruguai e das Missões (URI)

98.802-470 - Santo Ângelo - RS - Brasil

paludoesan.uri.br, deniro@san.uri.br, roquedsan.uri.br,

julianalima@san.uri.br, marinadbendsan.uri.br

\begin{abstract}
This article describes an experiment conducted with high school girls from public and private schools in a city of Rio Grande do Sul, in order to stimulate computational thinking and to bring them closer to the computing area. The strategy used focuses on the application of educational robotics as a way to expand possibilities, seeking learning through individual reflection and group interaction. A description of the methodology applied and the results obtained is presented so that the experiment can be improved and replicated.

Resumo. Este artigo descreve uma experiência realizada com alunas do ensino médio de escolas públicas e privadas em um município do Rio Grande do Sul, com o intuito de estimular o pensamento computacional e aproximá-las da área de computação. A estratégia utilizada concentra-se na aplicação da robótica educacional como forma de ampliar as possibilidades, buscando o aprendizado por meio da reflexão individual e da interação em grupo. Uma descrição da metodologia aplicada e dos resultados alcançados é apresentada de modo que a experiência possa ser aprimorada e replicada.
\end{abstract}

\section{Introdução}

A inovação tecnológica é um dos sinais que marcam e melhor caracterizam os nossos quotidianos e os seus efeitos fazem sentir-se de forma generalizada em todos os setores da atividade humana. A escola não é imune aos seus efeitos, antes pelo contrário, ela é crescentemente influenciada pela "sociedade do conhecimento" e vem sendo constantemente instigada a implementar estratégias que fortaleçam o elo entre Ciência, Tecnologia e Educação.

Dentre os diversos desafios que permeiam as discussões na esfera educacional, há dois deles que nos parece importante evidenciar visto que afetam diretamente as escolas, bem como a própria Universidade. O primeiro deles está relacionado à disseminação do pensamento computacional no ensino básico e, o segundo, refere-se à baixa representatividade feminina nas carreiras de ciência, tecnologia, engenharia e matemática (STEM) [Sullivan, 2013][Grover, 2013].

Espera-se da escola iniciativas que permitam proporcionar a todos uma educação moderna e atualizada, incluindo propostas para a formação de indivíduos capazes de se adaptar às rápidas mudanças tecnológicas, e que saibam entender, utilizar e também desenvolver tecnologias de forma crítica, inovadora e criativa. Nesta perspectiva inserem-se as inúmeras discussões acerca da reformulação das diretrizes curriculares com vistas a introdução do pensamento computacional na educação básica como forma de ampliar as habilidades e competências de crianças e jovens 
VIII Congresso Brasileiro de Informática na Educação (CBIE 2019)

Anais do XXV Workshop de Informática na Escola (WIE 2019)

contemplando novos paradigmas no processo de ensino e de aprendizagem [Wing, 2016][Bocconi, 2016].

O desenvolvimento do pensamento computacional neste sentido não se reduz à ideia de uso da tecnologia, softwares, equipamentos, redes, etc., mas corresponde a um modo estruturado de raciocínio usado na resolução de problemas que inclui pensamento recursivo, abstração, automação, decomposição, modelagem, simulação, dentre outros [Selby, 2013] [Vallance, 2018]. Embora esses princípios façam parte das capacidades essenciais dos cientistas da computação, muitos deles são igualmente fundamentais para cientistas de outras áreas e também igualmente importantes, de forma transversal, para pessoas em geral considerando que estas capacidades constituem um conjunto de ferramentas mentais que podem e são usados no quotidiano das pessoas.

Apesar de existirem iniciativas que ao longo dos últimos anos matizaram novas abordagens pedagógicas permeadas pela inserção das Tecnologias de Comunicação e Informação (TICs) e popularização do pensamento computacional, os problemas ainda persistem [Yurdugül, 2013] [Kalelioğlu, 2015]. A falta de habilidades e competências técnicas para o uso das tecnologias, a resistência à aquisição de uma nova postura por parte dos professores, o tempo dispendido para elaboração de material instrucional, a escassez de ferramentas para a área tecnológica nas escolas e a falta de um suporte efetivo das instituições aos professores são alguns dos entraves que ainda permanecem no universo escolar e que requerem a implementação de estratégias com vistas a superar tais barreiras e desafios.

Associados as atuais discussões sobre a necessidade da popularização da ciência e tecnologia e a inclusão do pensamento computacional no contexto escolar estão os debates acerca do hiato de gênero que persiste nas carreiras científicas e tecnológicas [Atmatzidou, 2016][Maciel, 2016]. Mesmo com uma longa história de sucesso que as mulheres já alcançaram como pioneiras na ciência da computação, torna-se desconcertante saber que tão poucas estão envolvidas no campo atualmente [Guedes, 2016].

Embora sejam várias as conquistas que refutam qualquer discurso que desmereça a capacidade feminina e provam que as mulheres cientistas não faltam na História, ainda no século XXI a herança de determinados conceitos influência tanto nas ações das mulheres quanto nos julgamentos sofridos por elas. Isto se estabelece em vários contextos da ciência, inclusive no universo da Ciência da Computação, que não se configura como uma exceção nesta esfera [Lima, 2013].

Nesse cenário, tanto a popularização da ciência e tecnologia por meio da disseminação do pensamento computacional quanto a disparidade de gênero existente nas áreas científicas e tecnológicas, configuram-se como elementos de investigação, sendo o cerne de várias iniciativas em nível nacional e internacional.

Vinculando a análise deste panorama ao contexto local tornam-se evidentes as limitações existentes nas escolas para a fomento de práticas que promovam a popularização do pensamento computacional, seja pela falta de capacitação dos professores [Ramos, 2014] ou pela escassez de recursos, bem como as demandas da própria Universidade no que se refere ao contingente reduzido de alunos nos cursos de Computação. Buscando contribuir para a ampliação de ações no sentido de popularizar o pensamento computacional e aproximar o público feminino das carreiras STEM, o projeto Meninas Digitais Tchê Missões, em sua $3^{\mathrm{a}}$ edição, concentrou suas atividades na aplicação da robótica como forma de ampliar as possibilidades, buscando o aprendizado por meio da reflexão individual e da interação em grupo. 
Uma descrição mais detalhada das ações desenvolvidas no escopo do projeto é apresentada nas seções subsequentes como forma de disseminar a experiência e possibilitar seu aprimoramento e replicação. A seção 2 descreve os procedimentos metodológicos empregados na execução do projeto; a seção 3 apresenta os resultados obtidos e a, por fim, a seção 4 apresenta as considerações finais.

\section{Procedimentos Metodológicos}

As atividades propostas alinham-se aos pressupostos da Robótica Educacional Livre como ferramenta mediadora do processo de aprendizagem, valorizando o planejamento, pesquisa, interesse, motivação e cooperação entre as alunas, através de uma rica experiência interdisciplinar, uma vez que envolve diferentes áreas de conhecimento e pessoas na resolução de problemas; além de soluções livres em substituição aos produtos comerciais.

A ação inicial envolveu uma mobilização no ambiente escolar para divulgação do projeto e a organização de uma agenda que permitisse a participação do maior número possível de alunas. Cada escola foi convidada a indicar uma equipe feminina compostas por 5 a 10 integrantes do ensino médio. Enfatizou-se que a adesão das meninas à proposta deveria ser espontânea, sabendo que seguirão uma metodologia que as coloca como protagonistas e que lhes abre a oportunidade de ampliar seus conhecimentos.

Para cada equipe participante foi disponibilizado um kit robótico, denominado Robô Sumô Arduino UR20, que apresenta todas as peças necessárias para construção do chassi base, bem como sensores para detecção de objetos, roda dianteira do tipo esfera, motores com caixa de redução, além de rodas emborrachadas para deslocamento. O Chassi é produzido inteiramente em MDF com 3mm de espessura, o que aumenta sua resistência, durabilidade e possibilita que o projetista faça perfurações extras para fixação de outros sensores ou mesmo de uma chapa frontal. Entre os itens que acompanham o kit Robótica estão parafusos, espaçadores, suporte de pilhas, conector de bateria, jumpers para conexão, chaves alavanca, sensores infravermelhos, sensor ultrassônico de distância, driver duplo Ponte H de motor DC, Arduíno Uno R3, cabo USB, barra de pinos, dentre outros acessórios necessários para a montagem do kit. A Figura 1 apresenta o kit disponibilizado para as equipes. Também acompanham os kits 2 carenagens impressas em 3D que podem ser utilizadas para customização dos robôs tanto no que se refere à estética, quanto à funcionalidade e proteção das demais peças.

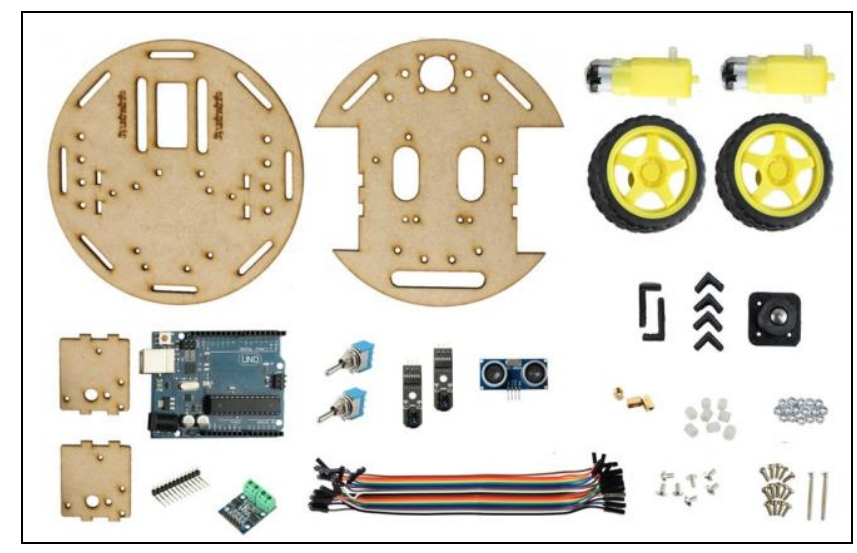

Figura 1. Kit Robótico disponibilizado para as equipes femininas

A atividade inicial de cada equipe consiste na montagem do robô. Para auxiliar esta atividade foram confeccionados e disponibilizados vídeos instrucionais e um manual ilustrado 
destacando o passo-a-passo da montagem. A Figura 2 apresenta um trecho do material confeccionado e disponibilizado para as equipes.

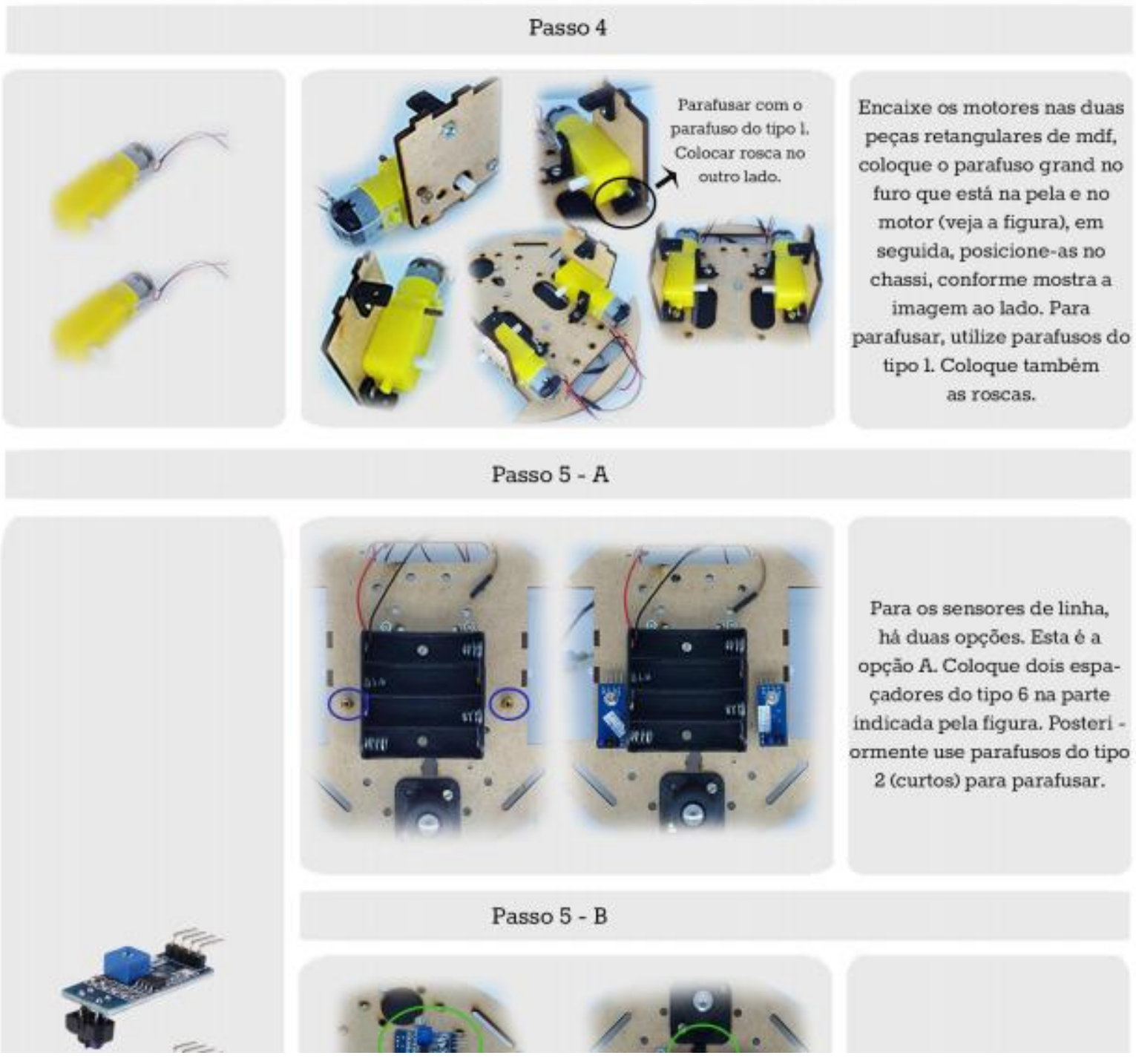

Figura 2. Trecho do Manual de Montagem do kit robótico

É importante salientar que no caso de dúvidas ou dificuldades na atividade de montagem do robô as equipes puderam contar com o auxílio de acadêmicas dos cursos de Ciência da Computação e Sistemas de Informação que integram a equipe executora do projeto.

Findada a etapa de montagem do robô, iniciaram-se as oficinas e ateliers de programação em que foram apresentados na prática como os conhecimentos de programação, física e matemática são empregados para a fabricação e programação de robôs. As oficinas foram inicialmente oferecidas para as acadêmicas bolsistas que integram a equipe do projeto de modo que as mesmas se tornassem multiplicadoras do processo de ensino.

Para a execução das oficinas e ateliers de programação optou-se pela adoção de uma metodologia ativa de ensino. Para tanto utilizou-se como recursos pedagógicos uma série de materiais instrucionais no formato de vídeos, canais de comunicação e fórum de discussão. A partir disso, as atividades relacionadas à programação do robô puderam ser desenvolvidas 
respeitando o tempo de aprendizagem de cada equipe, bem como suas disponibilidades de horários adaptável ao turno inverso de aula. Além disso, mediante demanda das equipes foram agendados atendimentos presenciais no laboratório de robótica da Universidade, em que foram sanadas dúvidas de cada uma das equipes participantes. Cabe destacar também, que os encontros presenciais serviram também para execução de testes e ajustes na programação dos robôs. A Figura 3 apresenta registros fotográficos de encontros presenciais realizados com as equipes.

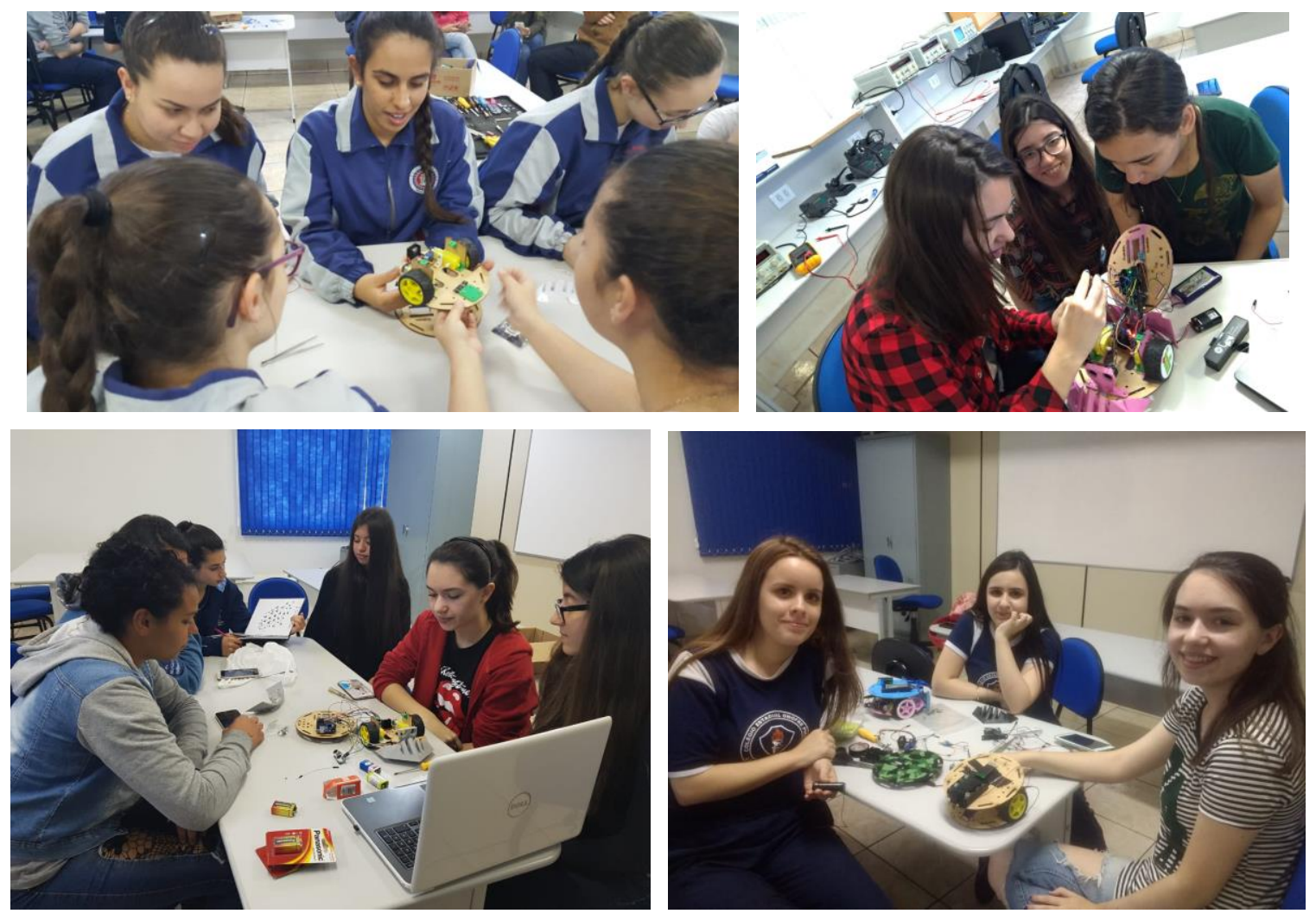

Figura 3. Encontros presenciais realizados com as equipes

As ações do projeto culminaram na participação das equipes de todas as escolas em uma Competição realizada na Universidade. A competição, no formato "Sumô", consiste na presença de dois robôs em uma pequena arena circular realizando ações que foram programadas e embarcadas nos robôs pelos competidores, com o intuito de permanecer dentro da arena por um tempo determinado. O Sumô de Robôs pode ser visto como um desafio típico para um robô autônomo de exploração que tenha, como limite de percurso, uma plataforma circular limitada lateralmente e cuja tarefa seja a remoção de seu oponente que possui igual objetivo. A dinâmica do desafio exige que se respeitem quatro condições: 1. A partida tem início simultâneo para os dois oponentes; 2. Não se pode, deliberadamente, buscar provocar danos no robô oponente; 3 . A retirada do oponente da arena é o objetivo único desse desafio; 4 . O desafio tem um tempo limite para ser resolvido.

Um regulamento foi elaborado e disponibilizado para as competidoras. Dentre as principais regras que o compõe destacam-se:

- Poderão participar da competição equipes previamente cadastradas pela escola participante, formadas exclusivamente por meninas e que tenham participado da oficina de robótica e atelier de programação promovidas pela Universidade. 
VIII Congresso Brasileiro de Informática na Educação (CBIE 2019)

Anais do XXV Workshop de Informática na Escola (WIE 2019)

- Dada a arena relatada na ficha técnica do desafio, a mesma deve estar posicionada de forma fixa e segura no chão ou em plataforma de apoio. Durante a partida, com exceção do árbitro e de um integrante de cada equipe (estes apenas na hora de ligar o robô), nenhuma pessoa poderá permanecer dentro dos limites estipulados pela organização da competição. O capitão da equipe será o responsável por ligar o robô.

- Cada robô deve ser obtido junto à organização da competição e após a sua montagem, deve caber sempre, sem necessidade de exercer força, numa caixa de base quadrada de lados iguais a 30,0 cm e altura de 22,0 cm. Cada robô deve possuir no máximo $1 \mathrm{Kg}$ (o peso atual do robô montado é de 560 gramas).

- Toda mudança ou personalização no Robô deve ser consultada a comissão responsável pela competição, para fins de manter o correto funcionamento do Robô;

- Será admitida a troca dos motores do robô, sendo responsabilidade de cada equipe adaptálo, devendo manter o restante do chassi atual;

- Sensores podem ser adicionados ao robô, sendo responsabilidade da equipe a aquisição e ajuste físico no chassi;

- É permitida a troca e adaptação de outras baterias no Robô (Ex: Lipo), desde que respeitadas as especificações de tensão de alimentação necessárias para o correto funcionamento dos componentes eletrônicos;

- Durante a montagem cada competidora pode melhorar as ligações dos componentes, de forma a agregar maior robustez e confiabilidade ao robô.

- Não devem ser inseridas peças metálicas na estrutura do robô;

- Respeitando o limite de peso do robô, cada competidora pode inserir partes que auxiliem na identificação ou estilização do robô (exemplo: bandeirinha com o nome do robô, adesivos para identificação ou personalização);

- Serão admitidas peças plásticas, fitas isolantes, apenas com o intuito de proteção de componentes, respeitando os limites de dimensões e peso do robô;

- Cada Robô deve ter obrigatoriamente alguma identificação da Escola (logos, brasões, símbolos, etc.).

- Para o computo dos pontos, cada waza-ari vale 10 pontos, cada yoko vale 6 pontos, cada koka vale 4 pontos e cada yusei-gashi vale 2 pontos.

Foram premiadas as 3 equipes que obtiveram a maior pontuação, e também a equipe que apresentou o robô mais estilizado. A Figura 4 apresenta registros dos robôs estilizados pelas equipes participantes. 

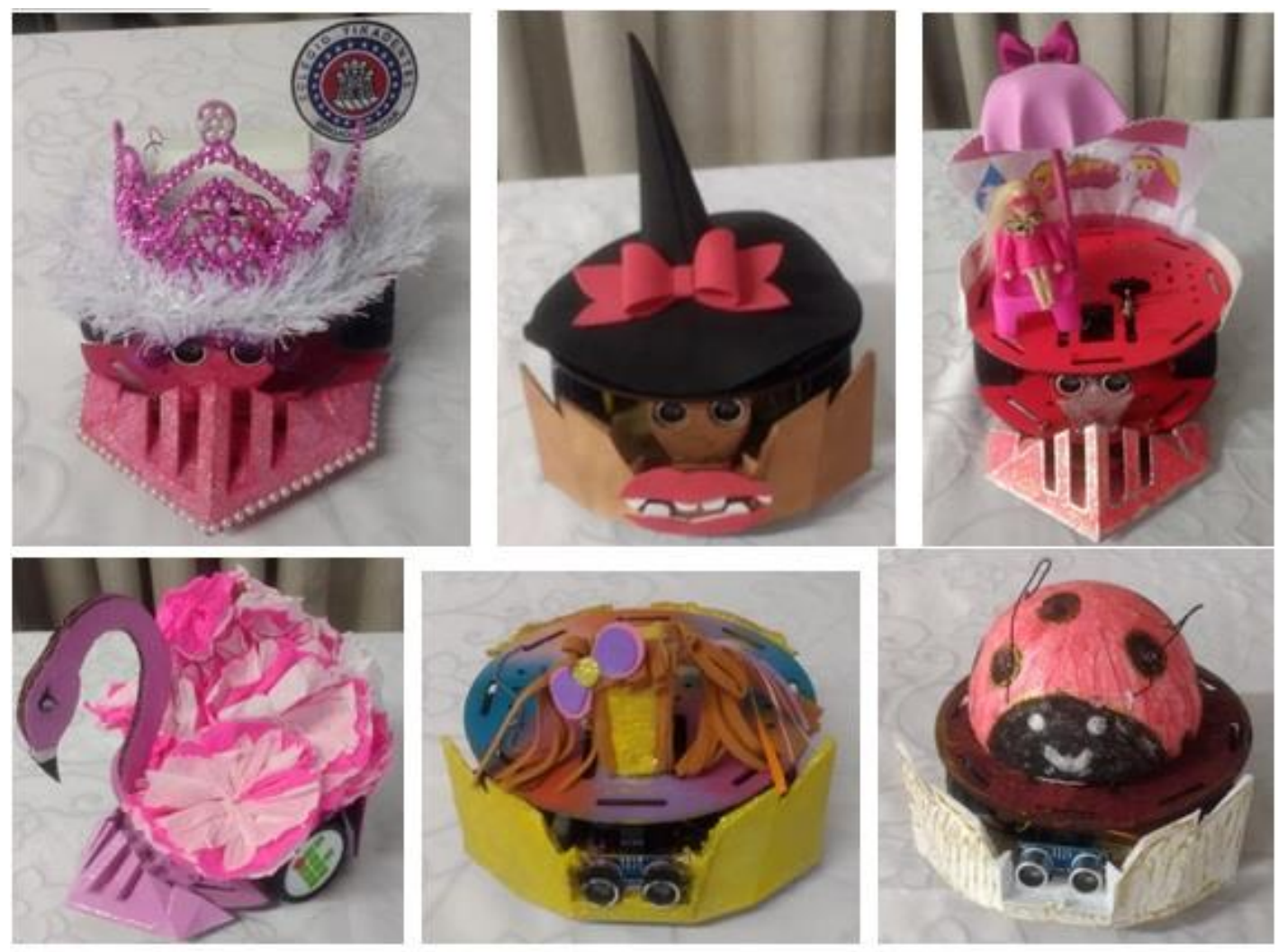

Figura 4. Robôs estilizados

$\mathrm{O}$ prêmio consistiu de troféus e medalhas. Todas as equipes receberam certificado de participação e um pôster confeccionado pela Universidade com a foto de todas as integrantes da equipe.

\section{Resultados Obtidos}

O projeto foi executado na instituição proponente e contou com a participação de 71 meninas, do $1^{\circ}$ ao $3^{\circ}$ ano do ensino médio, provenientes de escolas públicas e privadas do município e região. Os resultados desta experiência permitiram uma aproximação maior com a realidade das meninas no que se refere ao contato com a tecnologia.

Por meio de um instrumento de pesquisa elaborado com o intuito de avaliar as ações do projeto verificou-se que as meninas se sentiram motivadas em participar das atividades que envolvem a robótica, demonstrando interesse em futuras edições do projeto. Ao serem indagadas sobre sua percepção em relação ao projeto algumas declarações foram:

"O projeto proporciona o descobrir de uma área que normalmente não temos acesso" (S.F.S, $\mathbf{1}^{\circ}$ ano, 15 anos)

"O contato com os robôs e a competição desperta a curiosidade e a vontade de aprender mais sobre a área, porque muitas vezes não temos interesse por falta de conhecimento" (C.A., $\mathbf{1}^{\mathbf{0}}$ ano, 16 anos)

"A robótica contribui para despertar o interesse em computação, pois apresenta uma forma legal e divertida de aprender a construir e programar o robô, o que não temos contato no cotidiano escolar" (M.P.S, $3^{\circ}$ ano, 18 anos) 
VIII Congresso Brasileiro de Informática na Educação (CBIE 2019)

Anais do XXV Workshop de Informática na Escola (WIE 2019)

"Montando e programando o robô o aluno pode gostar de trabalhar com esse assunto e se interessar em uma formação na área" (J.O., $3^{\circ}$ ano, 18 anos)

"O projeto permite uma maior interação com a área de computação fazendo com que nos apropriemos de conceitos específicos e, com isso, percebemos que a área é bem interessante porque desperta nossa criatividade na resolução de problemas" (A.E.S., $2^{\circ}$ ano, 17 anos)

"Apesar de ser usuária da tecnologia, nunca pensei que poderia aprender a programar. $O$ projeto me aproximou da área e gostei muito. Podemos utilizar a criatividade na montagem do robô e temos que ter um raciocínio bem elaborado para que possamos programar o robô para que funcione corretamente. Com certeza quero aprender mais sobre o assunto" (P.P.S., $\mathbf{2}^{\mathbf{0}}$ ano, 17 anos)

Percebe-se, a partir das declarações que as expressões "desperta a curiosidade", "vontade de aprender mais", "não temos contato no cotidiano escolar", "a área é bem interessante" são recorrentes em vários dos depoimentos das meninas. Isto, juntamente com o número expressivo de meninas participantes, nos leva a crer que o atual universo tecnológico, predominantemente masculino, tende a se tornar mais igualitário com as novas gerações que já se familiarizam com a Ciência e Tecnologia trabalhadas na prática.

Outro ponto levantado no instrumento avaliativo foi em relação ao maior desafio encontrado pelas participantes em relação às ações propostas. Nesta questão foi unanime que a maior dificuldade foi na programação do robô e, a partir disso buscou-se verificar as causas de tais dificuldades. Dentre as opções disponíveis no instrumento constava: (a) Material instrucional incompleto ou confuso; (b) Encontros presenciais pouco esclarecedores; (c) Pouco tempo para programar o robô, (d) Falta de habilidades na programação e, (e) Dificuldade em encontrar os erros de programação. A partir das respostas obtidas pode-se verificar que o material disponibilizado, bem como o conhecimento das acadêmicas transmitidos nos encontros presenciais não foram apontados como as causas das dificuldades por nenhuma das participantes. O tempo de programação foi apontado como um empecilho para 45,07\% das meninas, o que nos permite rever o processo metodológico para as futuras edições, prevendo a ampliação do tempo para esta atividade dentro do projeto.

Além das percepções das meninas participantes em relação ao projeto, a opinião dos professores também se constitui como subsídio importante para o alinhamento das futuras ações do projeto. Nesse sentido, um instrumento avaliativo também foi elaborado e disponibilizado aos mesmos a fim de que pudessem contribuir com a melhoria do processo de ensino e de aprendizagem. Ao serem indagados sobre a sua percepção em relação as contribuições da robótica educacional no processo de ensino e aprendizagem no contexto escolar algumas declarações incluíram: "A robótica educacional contribui ao tirar as Ciências Exatas de um universo meramente teórico" (15 anos de magistério, formação matemática e física); " $A$ robótica utiliza e permite vivenciar inúmeros saberes e desenvolvimento cognitivo, próprio desse campo de saber, como por exemplo: criatividade, lógica, abstração, matemática, programação, entre outros. Além desses saberes a Robótica na escola é cativante, principalmente para os jovens" (32 anos de magistério, formação em matemática, física e mestre em Educação nas Ciências); "A robótica educacional é de suma importância pelo envolvimento dos professores $e$ alunos, afinal por meio dela todos aprendem, trocam e compartilham conhecimento, vitórias $e$ conquistas. Buscam coletivamente soluções para o desempenho do objeto de aprendizagem" (5 anos de magistério, formação em Licenciatura em Computação).

Quanto a opinião dos professores em relação as contribuições que o projeto pode 
promover no sentido de despertar novos talentos para a área de computação citam-se: “o projeto desperta no estudante o interesse por tecnologia no momento em que consegue integrar competição com um tema que parece tão distante da escola pública e assim as jovens conseguem visualizar uma realidade que não percebe em muitos espaços escolares"; “... muitas alunas que não faziam a mínima ideia do que se tratava a robótica, passaram a ter interesse"; "sem dúvida o projeto trará inúmeros resultados positivos de desenvolvimento e aprendizagem das alunas participantes".

Além das compreensões expostas, cabe destacar um resultado particularmente relevante. Por meio das ações desenvolvidas é perceptível o crescente interesse, principalmente das escolas públicas do município e região na incorporação das ações no ambiente escolar. Diretores, coordenadores pedagógicos e professores estão procurando a universidade, especialmente o curso de Ciência da Computação, para buscar apoio técnico e pedagógico com o objetivo de incluir, formalmente, a robótica educacional nos currículos escolares. Ou seja, a partir das ações do projeto, estão verificando possibilidades de articular os conteúdos de formação básica, como por exemplo matemática e física, com práticas que envolvam o projeto e programação de plataformas robóticas.

\section{Considerações Finais}

As ações propostas pelo presente projeto são fortemente ancoradas nas experiências vivenciadas e resultados obtidos ao longo dos últimos anos [Santos, 2017, 2018]. Por mais que os projetos desenvolvidos até o momento tenham promovido contribuições no sentido de aproximar jovens, e em especial meninas do universo científico e tecnológico, seus reflexos são lentos e podem ser percebidos pelo número ainda bastante reduzido de meninas ingressantes nos cursos de Computação da instituição. Isto nos conduz à ampliação das estratégias de ação promovendo a criação de uma cultura digital no universo escolar, com ações sendo executadas de forma perene, sistematizada e por meio de uma metodologia dialética.

Tecer espaços, como nos remete o título do artigo, constitui-se numa construção coletiva, pautada no respeito e na abertura ao diálogo. Acredita-se que a oportunidade promovida por este projeto é muito importante para que a Universidade possa estabelecer um vínculo mais profícuo e duradouro com as escolas, ao mesmo tempo que excita uma atuação e participação mais efetiva dos professores da Educação básica no sentido de provocar nos estudantes e, em especial, nas meninas, o desejo de compreender os "novos instrumentos tecnológicos" e suas potencialidades para resolver problemas da sociedade, além de considerar a área de computação, na sua amplitude de possibilidades, como escolha de um futuro profissional.

Tecer experiências nos reporta à constituição de grupos de trabalho com professores de diferentes níveis de ensino, os quais se assumem como comunidades de aprendizagem, superando a dissociação entre as práticas docentes e pesquisas acadêmicas e, alavancando novas abordagens em prol da popularização da Ciência e Tecnologia. A abordagem de experiências de desenvolvimento local é especialmente propícia para o atual cenário, ao permitir ensaiar com as escolas os processos participativos de assumir estratégias e de apoderar-se dos seus rumos. Além disso, é necessário considerar que este projeto foi realizado em uma região distante dos grandes centros, com baixo desenvolvimento econômico, com uma cultura pouco voltada ao olhar científico e tecnológico. Este cenário historicamente instituído, naturalmente não estimula a comunidade escolar a se movimentar para a realização e participação de ações correlatas a proposta deste projeto. Dessa forma, a Universidade assume um papel ainda mais relevante neste 
VIII Congresso Brasileiro de Informática na Educação (CBIE 2019)

Anais do XXV Workshop de Informática na Escola (WIE 2019)

cenário, pois acredita e já vem atuando com a intenção de modificar a cultura estabelecida, através de ações que possam ampliar os horizontes de possibilidades para a educação científica e tecnológica.

\section{Referências Bibliográficas}

Atmatzidou, Soumela; Demetriadis, Stavros. Advancing students' computational thinking skills through educational robotics: A study on age and gender relevant differences. Robotics and Autonomous Systems, v. 75, p. 661-670, jan. 2016.

Bocconi, Stefania et al. Developing Computational Thinking in Compulsory Education. [S.l: s.n.], 2016.

Grover, Shuchi; Pea, Roy. Computational Thinking in K-12. Educational Researcher, v. 42, n. 1, p. 38-43, jan. 2013.

Guedes, Vanessa; Lima, Ana Paula; Roos, Carine. A Revolução das Mulheres (2016). Disponível em: http://link.estadao.com.br/blogs/faca-voce-mesma/a-revolucao-das-mulheres/. Acesso em: 9/1/2017

Ramos, José Luís; Espadeiro, Rui Gonçalo. Os futuros professores e os professores do futuro. Os desafios da introdução ao pensamento computacional na escola, no currículo e na aprendizagem. Educação, Formação \& Tecnologias, NULL, v. 7, n. 2, p. 4-25, 2014.

Lima, Michelle Pinto. As mulheres na Ciência da Computação. Estudos Feministas, Florianópolis, 21(3): 496, setembro-dezembro, 2013.

Maciel, C. and Bim, S. A. (2016) Programa Meninas Digitais - Ações para divulgar a Computação para meninas do ensino médio, In: Computer on the Beach 2016, Florianópolis, SC. pp.327-336, 2016

Yurdugül, Halil; Aşkar, Petek. Learning Programming, Problem Solving and Gender: A Longitudinal Study. Procedia - Social and Behavioral Sciences, v. 83, p. 605-610, 2013.

Santos, Cristina Paludo, et al. "Desafio de programação para meninas do ensino médio: Um relato de experiência." Anais do Workshop de Informática na Escola. Vol. 23. No. 1. 2017.

Santos, Cristina Paludo, et al. "Desenvolvimento de Jogos Digitais como uma Estratégia para Despertar Novos Talentos: Um Relato de Experiência." Anais do Workshop de Informática na Escola. Vol. 24. No. 1. 2018.

Sullivan, Amanda; Bers, Marina Umaschi. Gender differences in kindergarteners' robotics and programming achievement. International Journal of Technology and Design Education, v. 23, n. 3, p. 691-702, 11 ago. 2013. Kalelioğlu, Filiz. A new way of teaching programming skills to K-12 students: Code.org. Computers in Human Behavior, v. 52, p. 200-210, nov. 2015.

Selby, Cynthia C. Computational Thinking: The Developing Definition. 2013, Canterbury, England: University of Southampton (E-prints), 2013. p. 6pp. Disponível em: <https://eprints.soton.ac.uk/356481/>.

Vallance, Michael; TOWNDROW, Phillip A. Mapping Computational Thinking for $a$ Transformative Pedagogy. Cham: Springer International Publishing, 2018.

Wing, Jeannette M.; Stanzione, Dan. Progress in computational thinking, and expanding the HPC community. Communications of the ACM, v. 59, n. 7, p. 10-11, 24 jun. 2016. 